\title{
Utilization of exhausted dust from FCC flue gas as material for FCC catalyst preparation
}

\author{
Zejun $\mathrm{Zuo}^{1,2}$ (1) $\cdot$ Lingling $\mathrm{Lv}^{3} \cdot$ Chenguang Liu ${ }^{1}$ Xingong Zhang ${ }^{3}$
}

Received: 11 May 2015/ Accepted: 7 July 2015/Published online: 29 July 2015

(c) The Author(s) 2015. This article is published with open access at Springerlink.com

\begin{abstract}
In this paper, new matrix and corresponding fluidized catalytic cracking (FCC) catalysts were prepared by reutilizing the exhausted dust which was derived from fluidized catalytic cracking flue gas. The results showed that the new matrix has wider mesopore size distribution than pseudo-boehmite binder. With the increase of the additional amount of this new matrix, FCC catalyst possessed increased micro-activity test conversion of vacuum gas oil (VGO) from $68 \%$ to $71 \%$. The catalytic cracking performance on a fixed fluidized bed unit showed that compared with CAT-1, the conversion of VGO on CAT-5 increased by $1.19 \%$, heavy oil yield and coke yield decreased by 2.16 and $1.65 \%$, respectively. Besides, the total liquid yield and light oil yield increased by 2.27 and $2.26 \%$, respectively. The reaction performance of CAT-3 and CAT-5 is obviously superior to CAT- 1 . The appropriate pore structures and crystallized Y zeolite component on this new matrix improve the cracking ability of FCC catalysts.
\end{abstract}

Keywords Matrix - Flue gas dust - FCC catalyst - Fixed fluidized bed

Zejun Zuo

huichengxu@163.com

1 State Key Laboratory of Heavy Oil Processing, China University of Petroleum, Qingdao 266580, Shandong, China

2 The Refinery of Zhongyuan Oilfield Company, SINOPEC, Puyang 457001, Henan, China

3 Qingdao Huicheng Petrochemical Technology Co., Ltd, Qingdao 266500, Shandong, China

\section{Introduction}

Air-particle pollution in China, which is caused by increasing fossil fuel consumption and industrial particulate emissions, gives rise to the deterioration of air quality and severe haze weather. Haze weather can cause serious harm to the respiratory system and cardiovascular system of humans and other creatures. The fluid catalytic cracking (FCC) unit is an important industrial particulate source $[1,2]$.

FCC process is one of the most important technologies to convert heavy oil into liquified petroleum gas (LPG), gasoline, and diesel. FCC catalyst with particle sizes in the range of $80-180 \mu \mathrm{m}$ cycles between FCC riser and regenerator for hydrocarbons cracking and reactivation [3]. However, due to the collision, hydrothermal collapse, and mechanical friction in recycle, spent FCC catalyst becomes dust and escapes with the FCC flue gas when its particulate size is less than $30 \mu \mathrm{m}$ (more than $50 \%$ is $<10 \mu \mathrm{m}$ ), leading to higher concentration of atmospheric particulate matter pollution. It is necessary to control the emission of FCC flue gas dust.

Element analysis shows that the spent catalyst dust is composed of alumina and silica as well as trace elements such as $\mathrm{Ni}, \mathrm{V}$, and $\mathrm{Fe}$ that comes from FCC feedstock. However, the traditional landfill of spent catalyst causes resource waste and soil pollution. In recent years, reports show that more spent catalyst has been reutilized to produce cement, flocculant, and wax hydrofining catalyst [4, 5]. Alumina and silica of flue gas dust originate from the FCC fresh catalyst. So, it is reasonable to reutilize the flue gas dust to prepare FCC catalyst referring to their compositional similarity [6].

This study aims to explore an environmental friendly and effective way to recycle the solid particle in FCC flue gas. Flue gas dust was first recrystallized to form a $\mathrm{Y}$ 
zeolite-containing new matrix. This new matrix was further used to prepare FCC catalyst by partial substitution of pseudo-boehmite binder. Finally, the catalytic cracking properties of the as-prepared FCC catalyst were tested in the conversion of vacuum gas oil (VGO).

\section{Experimental section}

\section{Raw materials}

Industrial pure raw materials, including sodium silicate $\left(\mathrm{Na}_{2} \mathrm{SiO}_{3} \cdot 9 \mathrm{H}_{2} \mathrm{O}\right)$, sodium hydroxide $(\mathrm{NaOH})$, alumina sol, and flue gas dust, were provided by the refinery of Zhongyuan Oilfield Company, SINOPEC. Rare earth Y zeolite (REY) was provided by Qingdao Huicheng Petrochemical Technology Co. Ltd. Kaolin clay was purchased from China Kaolin Company. Pseudo-boehmite and VGO was purchased from Shandong Aluminum Company and Luqing Petrochemical Company, respectively.

\section{Synthesis of new matrix and FCC catalyst}

FCC catalyst was synthesized following steps shown in Scheme 1.
The guiding agent for NaY synthesis was prepared by mixing sodium silicate, deionized water and sodium aluminate and then standing at $26^{\circ} \mathrm{C}$ for $17 \mathrm{~h}$.

The flue gas dust was retrieved from a commercial FCC unit. The dust was treated by acid and calcined at $700{ }^{\circ} \mathrm{C}$ for $1 \mathrm{~h}$ before use. A suspension of sodium silicate, sodium hydroxide and deionized water were stirred at $60{ }^{\circ} \mathrm{C}$ for $10 \mathrm{~min}$. Then the treated dust was added into the suspension as aluminum source and stirred at $60{ }^{\circ} \mathrm{C}$ for $40 \mathrm{~min}$. The $\mathrm{Na}_{2} \mathrm{O} / \mathrm{Al}_{2} \mathrm{O}_{3}$ mass ratio was changed from 3.2 to 9.0, respectively. Thereafter, the guiding agent was added into the above suspension and this suspension was continuously stirred and hydrothermally treated at $92{ }^{\circ} \mathrm{C}$ for $26 \mathrm{~h}$ to form the matrix precursor. New matrix containing zeolite was finally obtained after filtration, washing, and modification by $\mathrm{RE}_{2} \mathrm{O}_{3}$. And the chemical composition of the original dust and the new matrix is listed in Table 1.

The above zeolite-containing new matrix was adopted to partially replace pseudo-boehmite which plays the role of the binder in conventional FCC catalyst. Before use, the new matrix was lapped to be smaller than $5 \mu \mathrm{m}$ in particle size. New matrix, pseudo-boehmite, alumina sol, kaolin clay, REY, and water were mixed to be a suspension and stirred at room temperature for $24 \mathrm{~h}$. Finally, the new catalysts were prepared by the treatment of the mixture in a

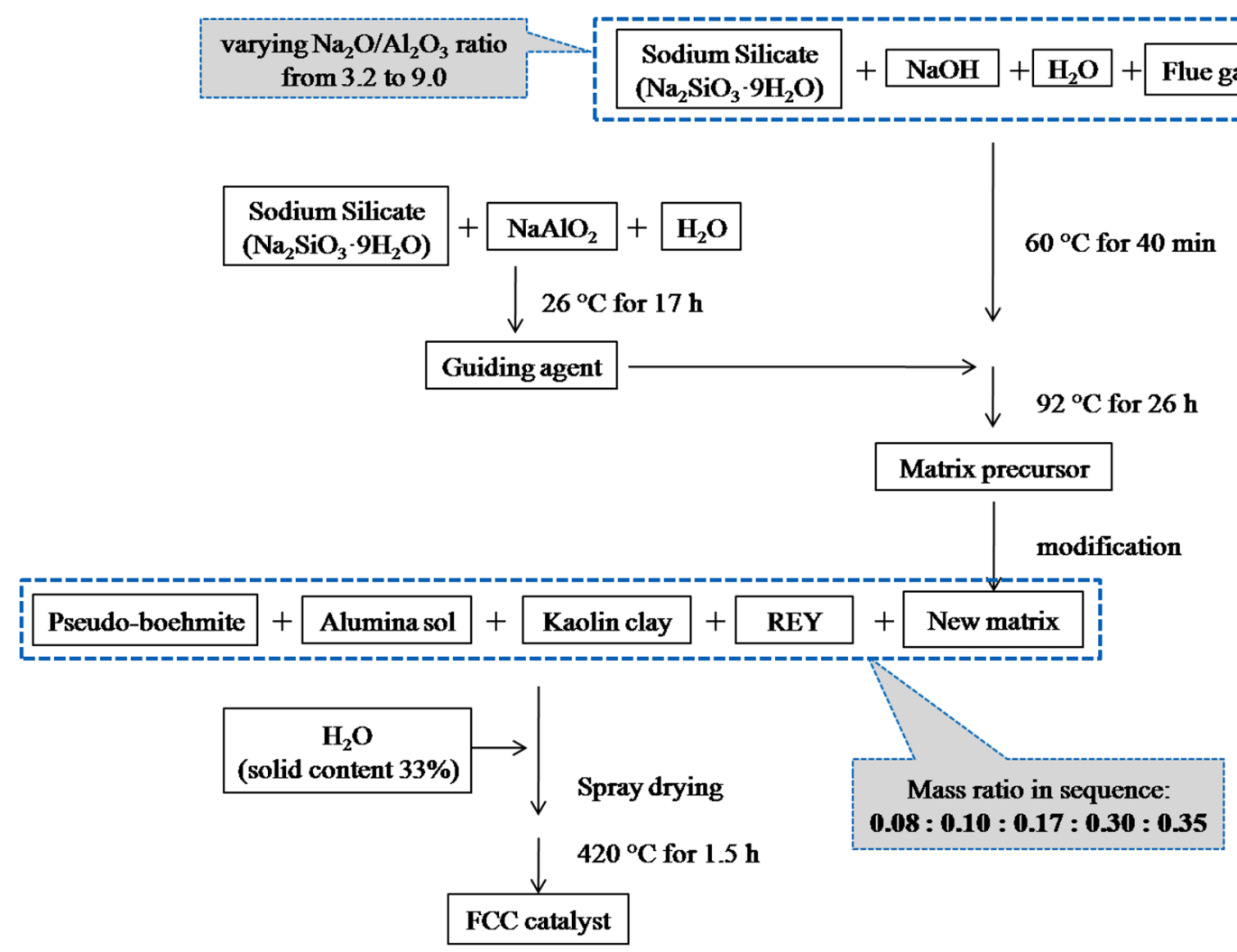

Scheme 1 The diagram of new matrix and FCC catalyst with flue gas dust 
Table 1 The chemical composition of the flue gas dust and new matrix

\begin{tabular}{lllrrrr}
\hline Items & $\mathrm{Al}_{2} \mathrm{O}_{3} / \%$ & $\mathrm{SiO}_{2} / \%$ & $\mathrm{Fe} / \mathrm{ppm}$ & $\mathrm{Ni} / \mathrm{ppm}$ & $\mathrm{V} / \mathrm{ppm}$ & $\mathrm{Ca} / \mathrm{ppm}$ \\
\hline Flue gas dust & 46.10 & 43.88 & 16,099 & 5830 & 2559 & 4328 \\
New matrix & 37.00 & 36.04 & 1431 & 773 & 81 & 1952 \\
\hline
\end{tabular}

Table 2 Properties of feedstock

\begin{tabular}{lr}
\hline Items & \\
\hline Density $\left(20^{\circ} \mathrm{C}\right)\left(\mathrm{kg} / \mathrm{m}^{3}\right)$ & 947.1 \\
Residual carbon $(\mathrm{wt} \%)$ & 5.89 \\
Group composition $(\mathrm{wt} \%)$ & \\
Saturates & 51.46 \\
Aromatics & 26.69 \\
Colloid & 19.97 \\
Asphaltenes & 1.88 \\
$\mathrm{Metal}$ content $(\mathrm{mg} / \mathrm{kg})$ & \\
$\mathrm{Ca}$ & 7.94 \\
$\mathrm{Fe}$ & 6.31 \\
$\mathrm{Na}$ & 13.71 \\
$\mathrm{Ni}$ & 10.02 \\
$\mathrm{~V}$ & 16.41 \\
\hline
\end{tabular}

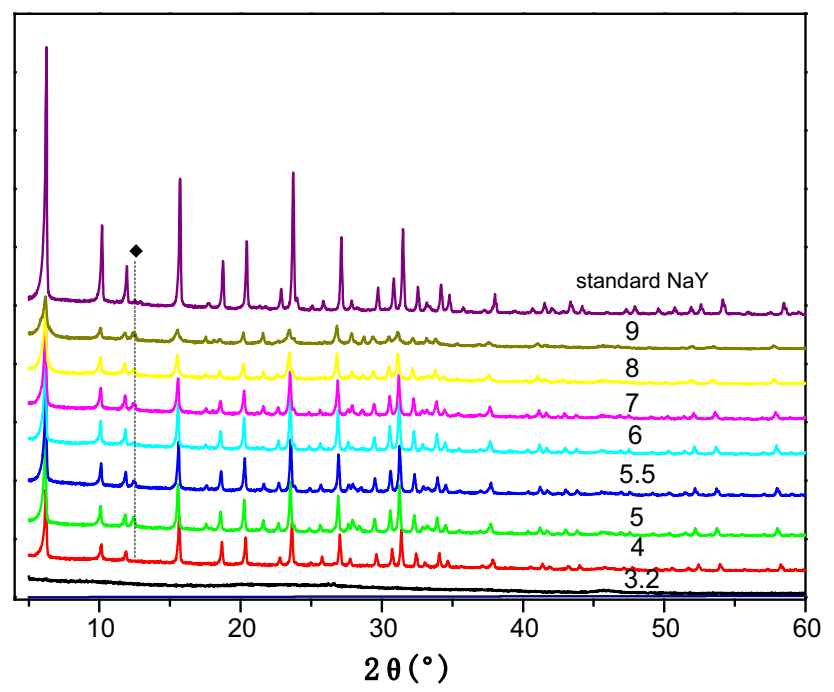

Fig. 1 XRD patterns of standard $\mathrm{NaY}$ and matrix (filled diamond) $\mathrm{P}$ zeolite

sequence of spray drying, washing, drying, and heating at $420{ }^{\circ} \mathrm{C}$ for $1.5 \mathrm{~h}$. The catalysts were marked as CAT-1, CAT-2, CAT-3, CAT-4, and CAT-5, respectively, depending on the solid mass ratio of the new matrix (varying from $0,2,4,6,8 \%$ ).

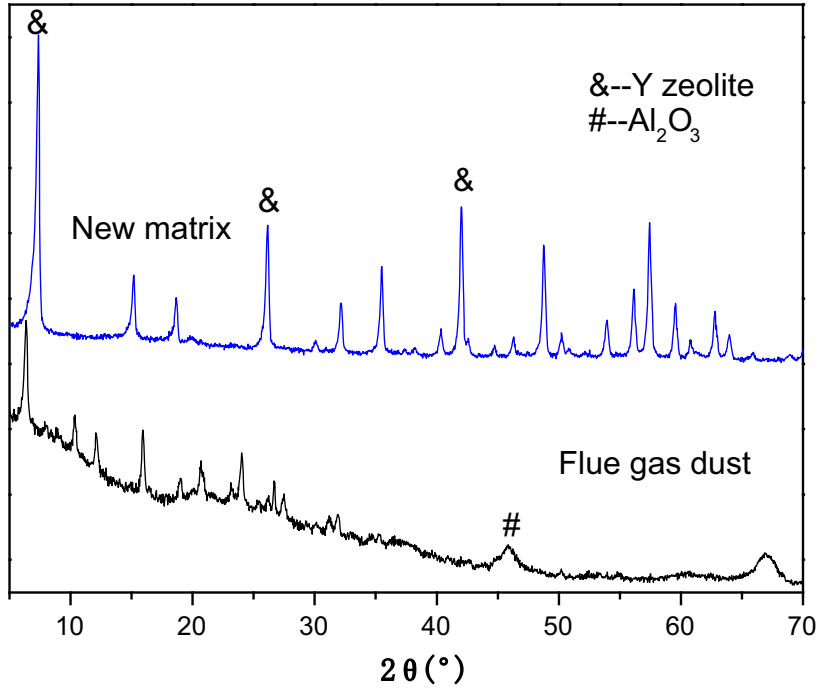

Fig. 2 XRD patterns of flue gas dust and new matrix prepared at $\mathrm{Na}_{2} \mathrm{O} / \mathrm{Al}_{2} \mathrm{O}_{3}$ ratio of 6.0

\section{Characterization}

XRD patterns were recorded on a Bruker Axs diffractometer (Germany) using $\mathrm{Cu}-\mathrm{K} \alpha$ radiation operating at $40 \mathrm{kV}$ and $40 \mathrm{~mA}$, scanning from $5^{\circ}$ to $75^{\circ}$ and at a speed of $0.01 \%$. $\mathrm{N}_{2}$ isothermal sorption measurements at $-196{ }^{\circ} \mathrm{C}$ were carried out on QUADRASORB SI analyzer. The samples were outgassed at $300{ }^{\circ} \mathrm{C}$ for $4 \mathrm{~h}$ with a vacuum pressure less than $10^{-2}$ torr prior to $\mathrm{N}_{2}$ sorption measurement. Specific surface area was calculated by the Brunauer-Emmett-Teller (BET) method using experimental points in the relative pressure range of $0.05-0.25$ [7]. The pore volume and pore size distribution were derived from the desorption branch of sorption curves, using the Barrett-Joyner-Halenda (BJH) method.

\section{Catalytic evaluation}

Catalytic activity tests of catalysts were performed on an automated bench-scale micro-activity test (MAT) unit. $5 \mathrm{~g}$ of the prepared catalyst (treated at $800{ }^{\circ} \mathrm{C}$ for $17 \mathrm{~h}$ with $100 \%$ of water) was filled in a fixed-bed microreactor. The reactions occurred at $460{ }^{\circ} \mathrm{C}$ for $70 \mathrm{~s}$ in a tubular stainless steel reactor with $1.56 \mathrm{~g}$ feed. Vacuum gas oil (VGO) as heavy hydrocarbon feedstock.VGO was purchased from 


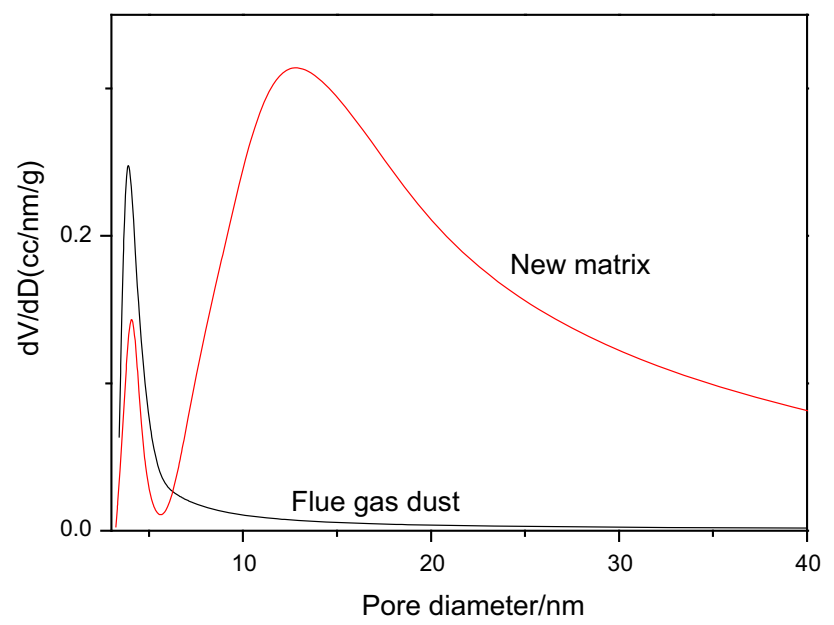

Fig. 3 Pore size distributions of flue gas dust and new matrix prepared at $\mathrm{Na}_{2} \mathrm{O} / \mathrm{Al}_{2} \mathrm{O}_{3}$ ratio of 6.0

Qing Dao An Bang Refinery Co. Ltd. (Table 2 as provided by vendor). The resulting cracking products were collected and analyzed by a SHIMADZUN2000 gas Chromatograph (GC) analyzer equipped with a flame ionization detector (FID).

The effects of the addition of zeolite-containing matrix on catalytic performances of new FCC catalysts were further tested on a fluid fixed bed (FFB) unit. The catalysts were first hydrothermally treated at $800{ }^{\circ} \mathrm{C}$ in a $100 \%$ water steam for $17 \mathrm{~h}$ before testing. The resulting liquid products and gases were analyzed by Agilent GC analyzer. The amount of coke deposited on the spent catalyst was measured by analyzing the quantities of $\mathrm{CO}_{2}$ and $\mathrm{CO}$ after combustion.

\section{Results and discussion}

The crystalline phases of the new matrix prepared with varying $\mathrm{Na}_{2} \mathrm{O} / \mathrm{Al}_{2} \mathrm{O}_{3}$ ratios were measured by XRD analysis shown in Fig. 1. All samples possess the characteristic peaks of Y-type zeolite, compared to $\mathrm{NaY}$ zeolite. However, there is another weak peak at $2 \theta$ degree of $12.5^{\circ}$ for all samples except the one with $\mathrm{Na}_{2} \mathrm{O} / \mathrm{Al}_{2} \mathrm{O}_{3}$ of 6.0. This peak is ascribed to the reflection of P-type zeolite at the similar $2 \theta$ position. $\mathrm{P}$ zeolite has thermodynamic steady state but it is ineffective in hydrocarbon cracking [3]. Therefore, the new matrix prepared at $\mathrm{Na}_{2} \mathrm{O} / \mathrm{Al}_{2} \mathrm{O}_{3}$ ratio of 6.0 was adopted to be further characterized and used.

To clearly compare the change of crystalline phases, the XRD patterns of flue gas dust and new matrix prepared at $\mathrm{Na}_{2} \mathrm{O} / \mathrm{Al}_{2} \mathrm{O}_{3}$ ratio of 6.0 were shown in Fig. 2. Flue gas dust possesses both alumina phase and $\mathrm{Y}$ zeolite phase, originating from the debris of wearing FCC catalyst in FCC system. In contrast, the new matrix has increased peak
Table 3 Textural properties of FCC flue gas dust and as-prepared new matrix

\begin{tabular}{llll}
\hline Sample & $\mathrm{S}_{\mathrm{BET}}\left(\mathrm{m}^{2} \mathrm{~g}^{-1}\right)$ & $\mathrm{S}_{\text {micropore }}\left(\mathrm{m}^{2} \mathrm{~g}^{-1}\right)$ & $\begin{array}{l}\text { Pore volume } \\
\left(\mathrm{cm}^{3} \mathrm{~g}^{-1}\right)\end{array}$ \\
\hline FCC flue gas dust & 81 & 56 & 0.09 \\
New matrix & 146 & 76 & 0.31
\end{tabular}

Table 4 Physical properties of FCC catalysts and their MAT conversion for VGO

\begin{tabular}{lllll}
\hline Sample & $\begin{array}{l}\text { Attrition } \\
\text { index }(\%)\end{array}$ & $\begin{array}{l}\mathrm{S}_{\mathrm{BET}} \\
\left(\mathrm{m}^{2} \mathrm{~g}^{-1}\right)\end{array}$ & $\begin{array}{l}\text { Pore volume } \\
\left(\mathrm{cm}^{3} \mathrm{~g}^{-1}\right)\end{array}$ & $\begin{array}{l}\text { Conversion } \\
(\%)\end{array}$ \\
\hline Cat-1 & 0.6 & 223 & 0.37 & 68 \\
Cat-2 & 0.8 & 231 & 0.37 & 70 \\
Cat-3 & 1.0 & 243 & 0.38 & 70 \\
Cat-4 & 1.5 & 239 & 0.40 & 71 \\
Cat-5 & 2.3 & 246 & 0.41 & 73 \\
\hline
\end{tabular}
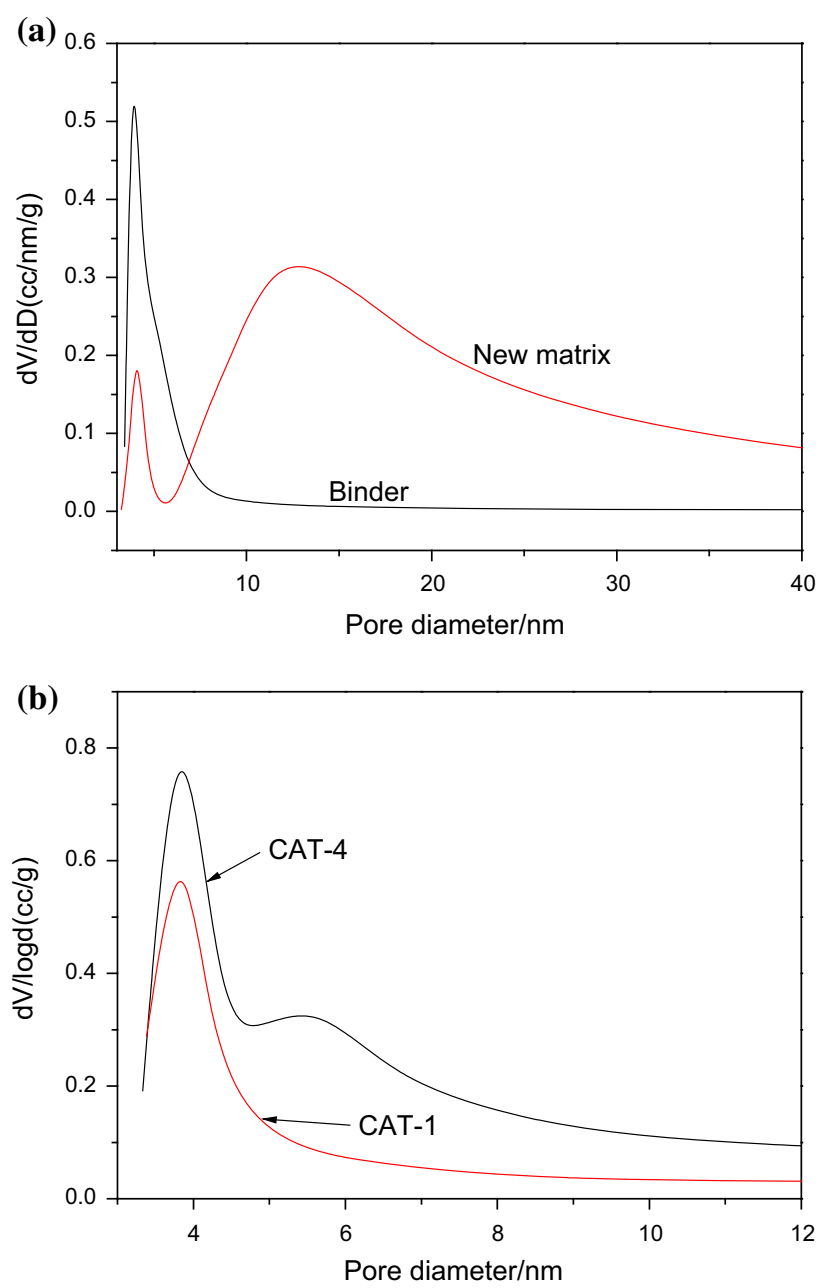

Fig. 4 Pore size distributions of a binder and new matrix, and $\mathbf{b}$ Cat1 and Cat-4, respectively 
Fig. 5 SEM images of asprepared FCC catalysts
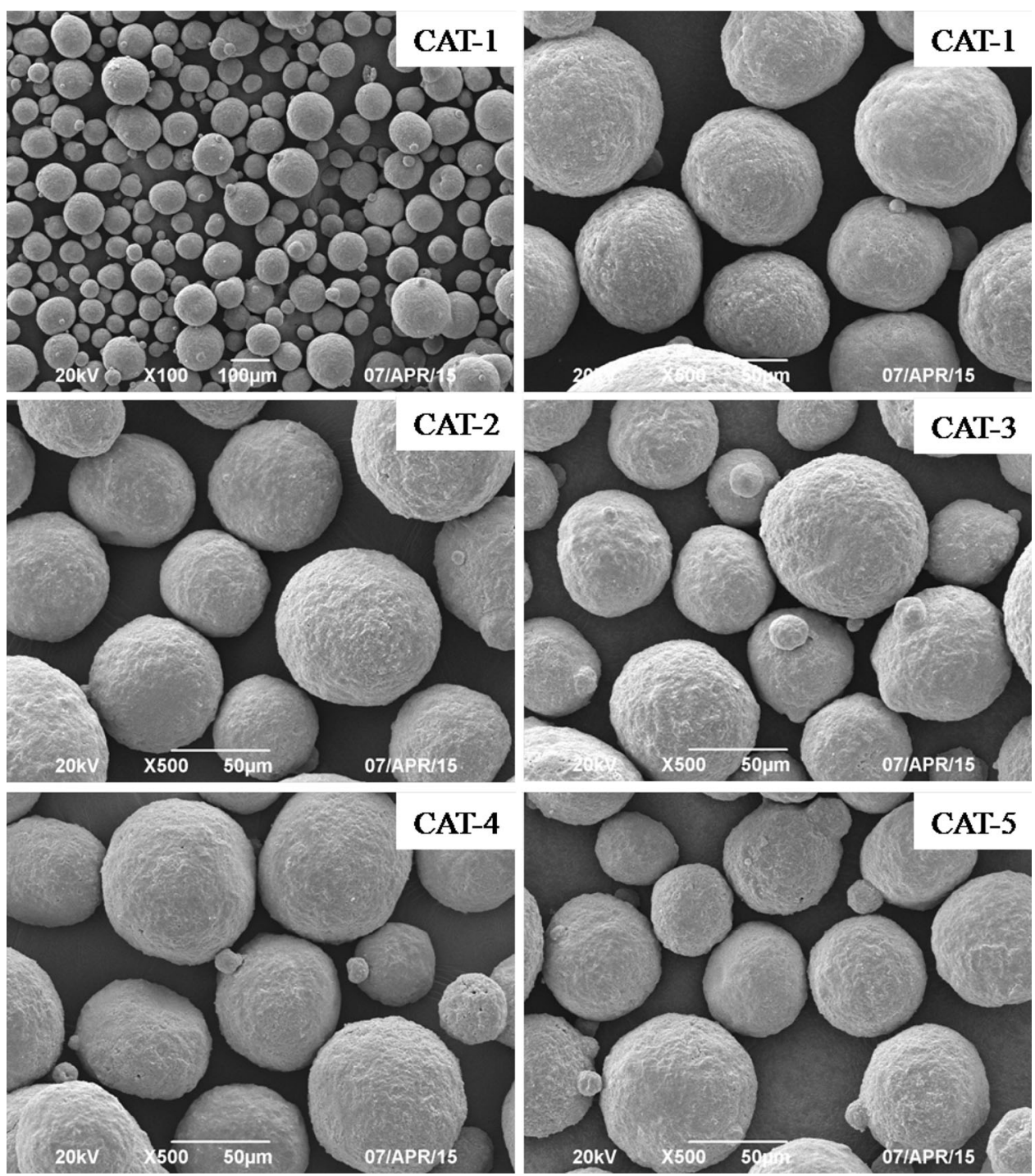

intensity of $\mathrm{Y}$ zeolite and undetected peaks of alumina phase. It indicates that the new matrix contains high content of $\mathrm{Y}$ zeolite by recrystallization in the presence of silica source, alumina source, and flue gas dust.

The results in Fig. 3 show that the new matrix possesses bi-model mesopores compared with the raw dust. Considering the crystalline phase in Fig. 2, the amorphous phase must be large in proportion to $\mathrm{Y}$ zeolite on the new matrix since $\mathrm{Y}$ zeolite has sole microporous structure. It coincides with the increases of total surface areas and micropore surface areas of new matrix compared with dust (Table 3).

The physical properties of FCC catalysts are shown in Table 4 . The results show that with increasing the addition of new matrix, the attrition index of FCC catalysts increased obviously while the surface areas and pore volumes slightly increase. It is attributed to the lower cohesiveness of the new matrix compared with pseudoboehmite binder. The attrition index of FCC catalyst is a key parameter and it represents the mechanical strength of catalyst. To some extent, the lower attrition index means longer lifetime of catalyst. The as-prepared FCC catalysts can meet the requirements of industrial application since their attrition index is less than the industrial limit value of 2.5. MAT conversion of VGO increases with increasing addition of new matrix in FCC catalysts (Table 4). It can be ascribed to the increase of the mesopore sizes of this new matrix and the $\mathrm{Y}$ zeolite content in the new matrix (Figs. 2, 4a)

The pore structure of catalyst is important for reactions. For FCC catalysts, three types of pores are involved according to the classification criterion by IUPAC. Micropores with pore diameter less than $2 \mathrm{~nm}$, which are provided by the active component such as $\mathrm{Y}$ zeolite, act as the main repository for hydrocarbon cracking. However, heavy oil molecules are too large to enter into the micropores for their diameters are in the range of 3-10 nm. It 
Table 5 Product distribution on different catalyts

\begin{tabular}{lrrr}
\hline Catalyst & CAT-1 & CAT-3 & CAT-5 \\
\hline Product distribution (wt\%) & & & \\
$\quad$ Dry gas & 1.64 & 1.62 & 1.61 \\
LPG & 17.10 & 17.10 & 17.11 \\
Gasoline & 41.83 & 41.58 & 42.69 \\
Diesel & 21.00 & 21.88 & 22.40 \\
Heavy oil & 10.62 & 9.14 & 8.03 \\
Coke & 9.81 & 8.68 & 8.16 \\
Total & 100.00 & 100.00 & 100.00 \\
Conversion (wt\%) & 68.38 & 68.98 & 69.57 \\
Light oil yield (wt\%) & 62.83 & 63.46 & 65.09 \\
Total liquid yield (wt\%) & 79.93 & 80.56 & 82.20 \\
\hline
\end{tabular}

turns out that the diffusion of molecules in porous channels is not limited when the optimized pore sizes are 2-6 times bigger than the diameter of molecules. Therefore, the macropores $(>50 \mathrm{~nm})$ inside new matrix contribute more effectively to the pre-cracking of heavy oil macromolecules compared to pseudo-boehmite binder (Fig. 4b). In contrast, the mesopores $(2-50 \mathrm{~nm})$, which are composed of secondary pores of zeolites and amorphous matrix, can be used for the cracking cycloparaffins and side-chain aromatics into light cycle oil (LCO). Besides, the acidity on mesopores should be mild and its numbers are usually limited.

SEM images (Fig. 5) show that all FCC catalysts have spherical particles. The addition of new matrix has no effect on the particle morphology.

CAT-1, CAT-3, and CAT-5 were tested on the FFB equipment to check the catalytic cracking peroperties of FCC catalysts with new matrix, and the results are shown in Table 5. It is obvious that FCC catalysts with new matrix have higher VGO conversions than conventional CAT-1 catalyst. Compared with CAT-1, the VGO conversion of CAT-5 increases by $1.19 \%$ while the coke yield decreases by $1.65 \%$. Besides, the diesel yield increases by $1.40 \%$ while heavy oil yield decreases by $2.59 \%$. As a result, the total liquid yield and light oil yield increased by 2.27 and $2.26 \%$, respectively. The overall reaction performances of CAT-3 and CAT-5 are obviously superior to CAT-1. The higher cracking ability of heavy oil is highly related with the properties of the new matrix.

\section{Conclusions}

An environmental friendly method was introduced to utilize the FCC flue gas dust in this study. A new matrix was first prepared with exhausted FCC flue gas dust. Then FCC catalysts were prepared by partial substitution of pseudoboehmite binder by this new matrix. Compared with conventional catalyst, the FCC catalysts with new matrix have better heavy oil conversion and coke selectivity, and increased light oil yield and total liquid yield. Therefore, the utilization of flue gas dust in this new strategy has a good application prospect and remarkable economic benefits.

Acknowledgments This work was financially supported by the Refinery of Zhongyuan Oilfield Company, SINOPEC and Qingdao Huicheng Petrochemical Technology Co., Ltd (Project No. 14-ZC0607-001)

Open Access This article is distributed under the terms of the Creative Commons Attribution 4.0 International License (http:// creativecommons.org/licenses/by/4.0/), which permits unrestricted use, distribution, and reproduction in any medium, provided you give appropriate credit to the original author(s) and the source, provide a link to the Creative Commons license, and indicate if changes were made.

\section{References}

1. Kulkarni P, Chellam S, Fraser MP (2007) Tracking petroleum refinery emission events using lanthanum and lanthanides as elemental markers for Pm2.5[J]. Environ Sci Technol 41(19):6748-6754

2. Bozlaker A, Buzcu-Güven B, Fraser MP et al (2013) Insights into Pm10 sources in Houston, Texas: role of petroleum refineries in enriching lanthanoid metals during episodic emission events[J]. Atmos Environ 69:109-117

3. Chen Junwu, Cao Hanchang (2005) Engineering and technology of fluid catalytic cracking [M]. Sinopec press, Beijing

4. Basaldella EI, Torres Sánchez RM, Conconi MS (2009) Conversion of exhausted fluid cracking catalysts into zeolites by alkaline fusion[J]. Appl Clay Sci 42(3-4):611-614

5. Elena IB, Julio CP, Mariana S et al (2006) Exhausted fluid catalytic cracking catalysts as raw materials for zeolite synthesis[J]. Appl Catal B 66(3):186-191

6. Liu X, Liang H, Li L et al (2010) Preparation of ultrafine y zeolite from spent fluid catalytic cracking catalyst powders[J]. Chin J Catal 31(7):833-838

7. Brunauer S, Emmett PH, Teller E (1938) Adsorption of gases in multimolecular layers[J]. J Am Chem Soc 60(2):309-319 